\title{
ИСТОРИЧЕСКИЕ ОСОБЕННОСТИ ФОРМИРОВАНИЯ
}

\section{НАЦИОНАЛЬНОГО ХОЗЯЙСТВЕННОГО КОМПЛЕКСА} ЮЖНО-АФРИКАНСКОЙ РЕСПУБЛИКИ

\section{Н.С. Загребельная, В.Н. Шитов}

Московский государственный институт международных отношений (университет) МИД России. Россия, 119454, Москва, пр. Вернадского, 76.

В статье анализируются специфические черты формирования аграрного и промышленного секторов Республики Южная Африка с момента образования Kanской колонии. Эти черты обусловлены с одной стороны гораздо более ранней колонизачией Юга Африки в сравнении с другими странами Африки южнее Сахары, а с другой - маситабным притоком на Юг Африки европейцев. Две наиболее значимые из этих специфических черт следующие. Первое: в отличие от других стран Африки южнее Сахары аграрный сектор изначально развивался на базе частной собственности и западных технологий. Второе: в нём отсутствует деление на «африканский» и «европейский» субсектора, а продукция южноафриканского сельского хозяйства всегда была ориентирована как на внешний, таки на внутренний рынок.

Развитие промышленного сектора Республики Южная Африка началось с добывающих отраслей; а именно алмазо- и золотодобычи. Авторы особенно отмечают рользолотодобычи, которая благодаря своемумультипликачионному эффектту положила начало промышленной револючии на Юге Африки. Становление обрабатывающей промышленности шло главным образом на базе импортозамещения. В статье выделяются несколько этапов импортозамещения и анализируются его результаты. Авторы указывают на особую значимость импортозамещения во время Первой и Второй мировых войн.

Ключевые слова: национальный хозяйственный комплекс, аграрный сектор, промышленный сектор, импортозамещение, Южно-Африканская Республика. 
B современных условиях Южно-Африканская Республика - это самое развитое государство не только в Африке южнее Сахары, но и во всей Африке. На ЮАР приходится менее 6\% населения Африки южнее Сахары, но её доля в совокупном валовом внутреннем продукте (ВВП) региона составляет свыше $22 \%$, в производстве промышленной продукции - $24 \%$, в производстве обрабатывающих отраслей около 27\%. Выгодно отличается Южно-Африканская Республика от других африканских стран и по уровню развития сельского хозяйства. Один занятый в аграрном секторе ЮАР создаёт добавленную стоимость в 6665 долл., в то время как аналогичный показатель по Африке южнее Сахары - 705 долл. [1]. Успехи в хозяйственном развитии ЮАР, несомненно, связаны с особенностями её экономической истории.

Формирование хозяйственного комплекса современной ЮАР началось со становления в XVII в. аграрного сектора Капской колонии [7]. Предназначенное первоначально для удовлетворения потребностей экипажей голландских, а позже британских судов, пережидавших шторма на пути в Аравию, Индию и Юго-Восточную Азию, сельское хозяйство Капской колонии получило сравнительно быстрое развитие. На момент создания Капской колонии, как и в регионе в целом, основу функционирования первичного сектора составляла община. Однако последующее развитие общинных отношений отличалось ярко выраженной спецификой, что было обусловлено гораздо более поздней (в последнее тридцатилетие XIX в.) колонизацией южноафриканской территории [9].

В большинстве африканских колоний общинные отношения, являвшиеся общественной формой функционирования наиболее примитивной хозяйственной деятельности (собирательство, а также охота и рыболовство с использованием простейших промысловых средств) постепенно эволюционировали и распространились на переложное земледелие и отгонно-пастбищное скотоводство [4]. В дальнейшем воспроизводство общинных отношений продолжилось, правда, простое, а не расширенное. Даже в современных условиях в большинстве стран Африки южнее Сахары община - это основа функционирования так называемого «африканского» сектора сельского хозяйства, значительного по своим масштабам и производящего традиционные продукты питания (например, клубнеплоды) для коренного населения. После колонизации в сельском хозяйстве был образован ещё и «европейский» сектор, основу которого составили плантационные хозяйства белых поселенцев, где выращивались исключительно экспортные культуры, пользовавшиеся спросом в метрополиях: из технических культур - каучконосы и хлопок, из продовольственных - какао и кофе. «Европейский» сектор развивался, по сути, в ущерб «африканскому», поскольку колониальные администрации отводили ему лучшие земли. Два сектора крайне слабо связаны друг с другом.

Развитие сельского хозяйства ЮАР проходило иначе. Аграрный сектор Капской колонии формировался на основе фермерских хозяйств буров ${ }^{1}$. Служащие голландской Ост-Индской компании, направленные в Капскую область для организации там, в дополнение к меновым операциям с коренным населением, сельскохозяйственного производства, получали в собственность от колониальной администрации земельные участки. В результате была создана система имущественных отношений на главный экономический ресурс того времени, крайне важная для развития сельского хозяйства юга Африки [2].

Другой особенностью развития аграрного сектора стало использование в фермерских хозяйствах буров труда рабов, завезённых главным образом из Азии. Дело в том, что отношения рабовладения никогда не были распространены в Африке южнее Сахары. Регион «не дорос» до рабовладельческого общества, оставаясь на патриархальной стадии развития. Конечно, африканские племена захватывали во взаимных военных столкновениях пленников, которые становились невольниками. Однако невольник и раб - совсем не одно и то же: невольники занимали в социальной иерархии такое же положение, что и младшие представители захватившего их африканского племени, и выполняли те же виды работ. Статус невольника (в отличие от статуса раба) не воспроизводился применительно к их потомкам.

Правда, рабовладельчество не составляло основу общественного производства на юге Африки, поскольку не было всеобщим [10]. Согласно общепризнанным энциклопедическим источникам, в середине XIX в. в Капской колонии только половина буров имела рабов, при этом в среднем на одного белого жителя приходилось примерно десять рабов [8]. В сравнении со скотоводством, в растениеводстве рабский труд был более распространён.

Постепенно буры перешли к использованию в сельском хозяйстве труда коренного населения. Изгнанные со своих исторических земель, формально свободные чёрные африканцы фактически были лишены средств к существованию. У той их части, которая не участвовала в набегах на фермы буров, оставался только один путь - стать наёмными работниками у белых. При этом коренным африканцам приходилось довольствоваться мизерным вознаграждением за свою тяжёлую работу. На деле их положение мало чем отличалось от положения рабов.

\footnotetext{
${ }^{1}$ Буры (от голландского boer - фермер) - название первых белых поселенцев на территории современной ЮAP.
} 
По своему характеру сельское хозяйство Капской колонии изначально было европейским, в корне отличавшимся от «европейского сектора» сельского хозяйства других колоний. «Европейский» сектор - это производство, ориентированное на экспорт в метрополию. Сельское хозяйство буров было ориентировано как на экспорт, через администрацию Капской колонии (и этим, главным образом, первоначально определялся его товарный характер), так и на внутреннее потребление, а именно на потребление самих буров [3].

Первой культурой, которую стали возделывать буры, стала пшеница. Она была нужна и самим бурам для выпечки хлеба, и экипажам заходивших в Капскую колонию вначале голландских, а затем британских судов для приготовления сухарей. Культивирование пшеницы шло с применением европейских технологий вспашки, сортировки семян, селекции всходов и т.д. Позже буры занялись выращиванием кукурузы, сорго, в дальнейшем ржи, ячменя и, наконец, сахарного тростника, также для внутреннего и внешнего рынков. В конце XVII в. с прибытием французских гугенотов начало развиваться винное виноградарство: не случайно долина недалеко от Кейптауна в современной ЮАР, где производят вина, называется на африкаанс Franschhoek, что в переводе означает «французский уголок» [11]. С французскими и немецкими переселенцами связано появление экзотических для Африки южнее Сахары фруктов субтропического и умеренного поясов (яблок, груш, персиков, абрикосов, слив, цитрусовых) и овощей. Уместно отметить. что южнее Сахары только в Капской колонии субтропический климат. С британскими переселенцами связано появление немногочисленных чайных плантаций. Лишь в последнее время эти продукты, прежде всего, красные и белые сухие виноградные вина, а также чай заняли прочное место в экспорте.

Развитие отгонно-пастбищного скотоводства и мясного животноводства современной ЮАР повторяло тенденции южноафриканского растениеводства в части опоры на европейские технологии. Но были и особенности. Первоначально буры занялись разведением коз для производства вяленого мяса, столь востребованного в то время голландскими, а затем и британскими мореплавателями. Сейчас эти козы называются в ЮАР бурскими, хотя их разведением задолго до колонизации занималось коренное население. Считается, что этот вид животного, относительно неприхотливый и жизнестойкий, был первым, кого одомашнил человек для продовольственных нужд на юге Африки.

Во второй половине XIX в. британцы завезли на Юг Африки крупный рогатый скот индийского происхождения, но уже скрещенный с мясными европейскими породами. Так на южноафриканской территории получили распространение зебу, говяжье мясо которых отличается низким содержанием жира и которые составляют сегодня основу мясного животноводства ЮАР.

Британцы завезли ангорских коз, что привело к масштабному производству шерсти, не уступающей по качеству шотландской. Эта шерсть изначально производилась преимущественно на экспорт и продолжает пользоваться спросом на мировом рынке. Развитие овцеводства, в том числе каракулевого, связано преимущественно с британцами, а свиноводство - с немецкими переселенцами.

С европейскими переселенцами связано и становление рыболовства современной ЮАР. Конечно, коренные африканцы традиционно занимались примитивным ловом пресноводной рыбы в реках Лимпопо, Эландс и других. Можно предположить, что на своих пирогах чёрное население Юга Африки практиковало и крайне рискованную гарпунную морскую «охоту»у западного побережья Южной Африки, омываемого Бенгельским течением (главного района промысла даров моря в современной ЮАР). Но только в Южно-Африканском Союзе, а затем в Южно-Африканской Республике рыболовство (прежде всего, морское, но затем в известной степени и пресноводное) стало значимой отраслью хозяйства, поставляющей продукцию как на внутренний, так и на внешний рынки (последнее, правда, главным образом относится к морской рыбе и морепродуктам).

Подводя итог рассмотрению общего и особенного в развитии сельского хозяйства ЮАР и региона в целом, нельзя не прийти к главному выводу: развитие южноафриканского аграрного сектора (в отличие от аграрного сектора других стран Африки южнее Сахары) шло преимущественно по «европейскому» пути и базировалось на привнесённых белыми переселенцами технологиях. В результате по уровню эффективности сельское хозяйство ЮАР заметно превосходит сельское хозяйство других стран региона.

Ключевым моментом в формировании хозяйственного комплекса ЮАР стало развитие алмазо- и, особенно золотодобычи, положившее начало горнодобывающей промышленности. Добыча алмазов началась в 1867 г. после открытия месторождений в долине реки Вааль и существенно активизировалась после того, как в 1870 г. было обнаружено крупнейшее в мире месторождение в районе современного города Кимберли [6]. Однако велась она первое время индивидуальными старателями, а торговля алмазами носила крайне хаотичный характер. В целом добыча алмазов привела к обогащению части белого населения и тем самым способствовала первоначальному накоплению капитала для последующего промышленного развития. Тем не менее, её роль в обеспечении экономической трансформации территории нынешней ЮАР нельзя преувеличивать. Очень скоро британский предприниматель Сесиль Родс (современники называли его величайшим авантюристом и в 
честь него названа Родезия) выкупил права на алмазодобычу у старателей и в 1888 г. основал компанию Де Бирс (De Beers), ставшую монополистом в этой сфере. Уже в 1890 г. Сесиль Родс стал премьер-министром Капской колонии, так что добыча алмазов способствовала (помимо и прежде всего его личного баснословного обогащения) определённому укреплению экономического положения этой территории.

Другое дело - золотодобыча [5]. Месторождения золота были обнаружены в 1886 г. в районе Витватерсранд и, по сути, положили начало промышленной революции на южноафриканской территории. Открытие месторождений породило невиданную до того по своим масштабам иммиграцию в Южную Африку из Старого света. Если в 1870 г. белое население Южной Африки составляло менее 250 тыс. человек, то к 1891 г. оно выросло до более чем 600 тыс., а в 1904 г. превысило 1 млн человек [11]. По своему составу эта иммиграция была пёстрой, но значительную часть иммигрантов составляли специалисты горного дела.

Добыча золота начала быстро увеличиваться. Уже к 1898 г. на Южную Африку приходилось 1/5 всего общемирового производства [5]. Экспорт золота существенно превысил по стоимости экспорт алмазов. Доходы от него позволяли быстро наращивать денежные сбережения. Началось капиталообразование.

Для успешного функционирования золотодобывающей промышленности требовалась соответствующая инфраструктура, и в Южной Африке приступили к масштабному строительству коммуникаций и портов. Возникла насущная необходимость в транспортном сообщении района добычи с морскими портами экспортной отгрузки, и началось масштабное строительство железных дорог. Создание железных дорог потребовало развития другой отрасли горнодобывающей промышленности - угледобычи. Первыми были освоены месторождения в Капской колонии, затем - в провинциях Наталь и Трансвааль ${ }^{2}$. Вследствие увеличения численности населения усилился товарный характер сельскохозяйственного производства. Начали быстро развиваться пищевая промышленность и производства по выпуску всё более разнообразных потребительских товаров. Экономика Южной Африки стремительно менялась, уверенно продвигаясь от аграрной к агро-индустриальной.

Новый этап промышленного роста Южной Африки начался с образования в 1910 г. Южно-Аффриканского Союза - доминиона Великобритании, обладавшего большой самостоятельностью в экономической сфере. Правда, ключевые позиции в хозяйстве Южно-Африканского Союза занимали британские предпри- ниматели, ориентировавшиеся на Великобританию, заинтересованную в получении из своего доминиона минерального сырья, а не готовой продукции. Как следствие, промышленный рост шёл по пути расширения горнодобывающих производств, особенно добычи золота, металлов платиновой группы, а также алмазов.

В 1914 г. началась первая мировая война. Для Южно-Африканского Союза, не имевшего современной по тем меркам обрабатывающей промышленности, она означала существенное сокращение притока из Великобритании товаров с высокой добавленной стоимостью. Началось первое в истории Южной Африки (по сути, вынужденное) импортозамещение. Больших успехов оно не имело, но всё-таки продвинуло вперёд южноафриканскую обрабатывающую промышленность, по крайней мере в части пищевой промышленности и простейших производств для горных работ.

После окончания войны и вплоть до окончания мирового экономического кризиса 1929-1933 гг. трансформация хозяйства Южно-Африканского Союза происходила медленно. При этом восстановление мировой экономики стимулировало приток в Южную Африку прямых иностранных инвестиций, прежде всего в горнодобывающую промышленность. Помимо добычи золота, платины, каменного угля началась добыча ванадия, железной руды, никеля, хрома, марганца. Иностранный капитал пошёл и на участие в создании отдельных обрабатывающих производств, в частности мощностей по выпуску стройматериалов. Преимущественно за счёт бюджетных средств Южно-Африканского Союза были построены предприятия чёрной металлургии, высокую рентабельность которых обеспечили близость источников сырья и дешевизна рабочей силы. Создание металлургических производств потребовало развития энергетики. Строительство тепловых электростанций на дешёвом местном каменном угле также финансировалось из бюджета Южно-Африканского Союза. С участием иностранного капитала была несколько диверсифицирована химическая промышленность, чьё становление началось ранее, с производства взрывчатых веществ для горнодобывающей отрасли.

Вторая мировая война обусловила начало второго этапа импортозамещения в Южно-Африканском Союзе. Существенное развитие получили металлообработка, химическая промышленность, производство оружия и боеприпасов, текстильное производство и пищевая промышленность, производство оборудования для горнодобывающей промышленности. К концу войны экономика Южно-Африканского Союза уже характеризовалась высокой степенью самодостаточности. Средства для реализации

\footnotetext{
2 Провинции Наталь и Трансвааль существовали до административной реформы 1994 г. По современному делению бывшая провинция Наталь входит в Квазулу-Наталь, а территория Трансвааля поделена между провинциями Северо-Запад, Гаутенг, Мпумаланга и Лимпопо.
} 
политики импортозамещения давала оплата $\mathrm{Be}$ ликобританией поставок золота, железной руды, а в конце войны и урана.

В 1961 г. была образована Южно-Африканская Республика. 1960-1970-е гг. - это «золотой» период в развитии обрабатывающей промышленности ЮАР. Именно с 1960-х гг. начиналось размещение в ЮАР автосборочных предприятий основными европейскими и американскими компаниями - продуцентами автомобилей. За короткое время Южно-Африканская Республика утвердилась в качестве самого крупного производителя грузовых и легковых автомобилей на всём континенте.

Другой отраслью транспортного машиностроения, получившей в тот период быстрое развитие, было судостроение. Упор делался на создание судов для рыболовецкого флота страны и вспомогательных судов, предназначенных для работы в портах. Ещё одна отрасль, быстрое становление которой произошло в 1960-1970-е гг., станкостроение. Производственные предприятия, созданные в вышеназванных отраслях, принадлежали, главным образом, иностранному капиталу. Продолжавшееся в тот период быстрое развитие металлургии, авиационного, железнодорожного и автодорожного транспорта, портового хозяйства и электроэнергетики практически не выходило за рамки государственного сектора. Именно в тот период в ЮАР было начато строительство (1976 г.) первой (и пока единственной) на африканском континенте атомной электростанции (АЭС Коеберг), для которой были закуплены реакторы из Франции ${ }^{3}$. Первый энергоблок АЭС был запущен в 1984 г., а второй - годом позже.

1980-е гг. - это период, когда противодействие южноафриканской политике апартеида стало приносить ЮАР ощутимые негативные экономические последствия. Начался отток иностранного капитала, прежде всего из обрабатывающей промышленности. К этому добавилось продолжавшееся со второй половины 1970-х гг. снижение мировых цен на золото, главный экспортный товар ЮАР. Страна столкнулась с серьёзными экономическими трудностями, однако экономического коллапса не произошло. Более того, имело место импортозамещение, пусть и скромное. Например, именно в 1980-е гг. стали развиваться производства по выпуску компонентов, узлов и деталей для автомобилестроения, что в итоге привело к повышению доли национальной составляющей в автомобилестроении. Это произошло благодаря экономически выверенной промышленной политике государства, хотя и негуманной по отношению к чёрному и цветному населению.

После ликвидации режима апартеида и последовавшей отмены экономических санкций внешние условия развития экономики кардинально изменились к лучшему. Возобновился приток иностранного капитала. Если, например, в 1990 г. участие прямых иностранных инвестиций (ПИИ) в валовом капиталообразовании не было статистически выявлено, то уже в 1999 г. этот показатель составил 6,7\% [6] После отмены режима апартеида ПИИ направлялись в горнодобывающую и в обрабатывающую промышленность, а также в сферу услуг. Были созданы предприятия в сфере электроники и электротехники. Получили развитие нефтехимия, производство удобрений, фармацевтика, транспорт и связь. Увеличилось количество автосборочных предприятий с участием профильных иностранных компаний.

Начал быстро расти внешнеторговый оборот Южно-Африканской Республики, в том числе импорт из развитых стран, и прежде всего из западноевропейских государств и США, препятствия для торговых связей с которыми устранились. Товарный импорт ЮАР за 1990-1999 гг. вырос почти в 1,5 раза. Интересно отметить, что в международной статистике данные по товарному импорту ЮАР за 1990 г. приводятся только по Южноафриканскому таможенному союзу, т.е. ограничиваются поставками из Ботсваны, Лесото, Намибии и Свазиленда. Стал уверенно развиваться туризм. За 1990-1999 гг. численность посетивших ЮАР иностранных туристов возросла более чем в 6 раз [3].

Со второй половины 1990-х гг. проявляется тенденция к усилению экспортной ориентации в развитии несырьевых (обрабатывающих) производств и сельского хозяйства ЮАР. Страна перестаёт быть чистым импортёром капитала и переходит к его экспорту, первоначально в государства региона, а затем и в страны, находящиеся за пределами африканского континента. Постепенно экономика Южно-Африканской Республики всё больше приобретает черты развитого государства, отчётливо выделяясь по уровню экономического развития и структуре хозяйства от других стран Африки южнее Сахары.

\section{Список литературы}

1. World Development Indicators. Washington: The World Bank, 2001.

2. Elphick R., Giliomee H. (ed.). The Shaping of South African Society, 1652-1840. Wesleyan University Press, 2014.

3. Greyling L., Verhoef G. Slow growth, supply shocks and structural change: The GDP of the Cape Colony in the late nineteenth century //Economic History of Developing Regions. 2015. Vol. 30. №. 1. Pp. 23-43.

\footnotetext{
${ }^{3}$ Реактор разработала французская Société française d'ingénierie électronucléaire et d'assistance à l'exportation (SOFINEL), филиал EDF и Framatome.
} 
4. Marks S., Atmore A. Economy and society in pre-industrial South Africa. - Longman Publishing Group, 1980.

5. Meredith M. Diamonds, Gold and War: The Making of South Africa. - Simon \& Schuster, 2007.

6. Newbury C. W. The diamond ring: Business, politics, and precious stones in South Africa, 1867-1947. Oxford University Press, 1989.

7. Ross R. J. The origins of capitalist agriculture in the Cape Colony: A survey //William Beinart, Peter Delius and Stanley Trapido (eds.) Putting a Plough to the Ground: Accumulation and dispossession in rural South Africa, 1850-1930. 1986. Pp. 57-100. URL: https://openaccess.leidenuniv.nl/bitstream/ handle/1887/4262/1246876_049.pdf

8. The New Encylcopaedia Britannica. Vol. 27. 15th edition. London, 1993, P. 858.

9. Wilson, Monica, and Leonard Monteath Thompson, eds. The Oxford History of South Africa: South Africa to 1870. Vol. 1. Oxford: Clarendon Press, 1969.

10. Worden N., Crais C. C. Breaking the chains: slavery and its legacy in the nineteenth-century Cape Colony.Witwatersrand Univ Pr, 1994.

11. World Development Indicators. Washington: The World Bank, 2015. Tables 1.1, 3.3, 4.2.

\section{Об авторах}

Наталья Станиславовна Загребельная - к.э.н., учёный секретарь Совета МГИМО-Университета. E-mail: nzagrebelnaya@mail.ru.

Владимир Николаевич Шитов - д.э.н., профессор кафедры мировой экономики МГИМО-Университета. E-mail:shitov@mgimo.ru.

\section{HISTORY OF NATIONAL ECONOMIC SYSTEM FORMATION IN THE REPUBLIC OF SOUTH AFRICA}

N. Zagrebelnaya, V. Shitov

Moscow State Institute of International Relations 76, Vernadsky av., 119454 Moscow, Russia.

Abstract: The article analyses specific historic features of formation of agrarian and industrial sectors of Republic of South Africa since the establishment of Cape Colony. These features resulted from much earlier colonization of South Africa in comparison with other Sub-Saharan African countries on the one hand and from a large-scale influx of Europeans to the South Africa on the other hand. The two most important of these specific features are the following. First. Contrary to other countries of Sub-Saharan Africa development of the agrarian sector of Republic of South Africa was based on private property and western technologies from the start. Second. The sector is not divided into "African» and «European» sub-sectors, and South-African agricultural produce has always been oriented to both: external and internal markets.

Development of industrial sector of Republic of South Africa started with creation of extractive industries, namely: extraction of diamonds and of gold. The authors specifically emphasize the role of gold extraction which grace to its effect of multiplicator opened the way for industrial revolution in the South of Africa. Development of manufacturing was mainly based on import-substitution. The article argues that there were several stages of import-substitution and analyses their outcomes. The authors point out to the special importance of import-substitution during the period of I World War and II World War.

Key words: national economic system, agrarian sector, industrial sector, import substitution, Republic of South Africa.

\section{References}

1. World Development Indicators. Washington: The World Bank, 2001.

2. Elphick R., Giliomee H. (ed.). The Shaping of South African Society, 1652-1840. Wesleyan University Press, 2014.

3. Greyling L., Verhoef G. Slow growth, supply shocks and structural change: The GDP of the Cape Colony in the late nineteenth century. Economic History of Developing Regions. 2015. Vol. 30. №. 1. Pp. 23-43.

4. Marks S., Atmore A. Economy and society in pre-industrial South Africa. Longman Publishing Group, 1980.

5. Meredith M. Diamonds, Gold and War: The Making of South Africa. Simon \& Schuster, 2007.

6. Newbury C.W. The diamond ring: Business, politics, and precious stones in South Africa, 1867-1947. Oxford University Press, 1989. 
7. Ross R. J. The origins of capitalist agriculture in the Cape Colony: A survey. In William Beinart, Peter Delius and Stanley Trapido (eds.) Putting a Plough to the Ground: Accumulation and dispossession in rural South Africa, 1850-1930. 1986. Pp. 57-100. URL: https://openaccess.leidenuniv.nl/bitstream/handle/1887/4262/1246876_049.pdf

8. The New Encylcopaedia Britannica. Vol. 27. 15th edition. London, 1993.

9. Wilson, Monica, and Leonard Monteath Thompson, eds. The Oxford History of South Africa: South Africa to 1870. Vol. 1. Oxford: Clarendon Press, 1969.

10. Worden N., Crais C. C. Breaking the chains: slavery and its legacy in the nineteenth-century Cape Colony.Witwatersrand Univ Pr, 1994.

11. World Development Indicators. Washington: The World Bank, 2015. Tables 1.1, 3.3, 4.2.

\section{About the authors}

Natalya S. Zagrebelnaya - PhD in economics, scientific secretary of the Academic Council of MGIMO-University. E-mail: nzagrebelnaya@mail.ru.

Vladimir N. Shitov - doctor of science in economics, professor of the Department of World Economy of MGIMOUniversity. E-mail: shitov@mgimo.ru. 